\title{
Curcumin-supplemented yoghurt improves physiological and biochemical markers of experimental diabetes
}

\author{
Vânia O. Gutierres, Clara M. Pinheiro, Renata P. Assis, Regina C. Vendramini, Maria T. Pepato \\ and Iguatemy L. Brunetti* \\ Department of Clinical Analysis, School of Pharmaceutical Sciences, UNESP at Araraquara, UNESP - Univ Estadual Paulista, \\ Rua Expedicionários do Brasil 1621, Araraquara, CEP 14801-902, SP, Brazil
}

(Submitted 26 January 2011 - Final revision received 14 September 2011 - Accepted 14 September 2011 - First published online 9 November 2011)

\begin{abstract}
We investigated the effects of prolonged treatment of diabetic rats with curcumin-supplemented yoghurt on the physiological and biochemical changes associated with diabetes mellitus. An established metabolic cage model was used to assess these changes in three groups of streptozotocin-diabetic rats which had been administered, by gavage, curcumin blended into yoghurt in the doses of 30,60 and $90 \mathrm{mg} / \mathrm{kg}$ body weight (BW) per $\mathrm{d}$ (groups $\mathrm{DC}_{30}, \mathrm{DC}_{60}, \mathrm{DC}_{90}$ ) for $31 \mathrm{~d}$. One group of non-diabetic rats was also treated with $90 \mathrm{mg} / \mathrm{kg} \mathrm{BW}$ per d curcumin (NDC90). Three control groups of diabetic animals received water (DW), yoghurt (DY) and insulin at $27.78 \mu \mathrm{mol} / \mathrm{d}$ by subcutaneous injection (DI). Also, two groups of non-diabetic animals received water (NDW) and yoghurt (NDY). Groups DI and DC90 exhibited significant falls, relative to DW and DY, in food and water intake, urine volume, glycaemia, urinary urea and glucose, proteinuria, serum TAG and activities of aspartate and alanine aminotransferases, and higher hepatic glycogen and BW. These improvements were greater in DI than in DC90. No difference was observed in the serum levels of total cholesterol or HDL-cholesterol, or in the masses of adipose and muscular tissues, between DC90 and DW or DY. Moreover, the improvements in curcumin-treated rats, relative to DW and DY, were significant and dose-dependent. The NDC90 group also showed no difference from the NDW or NDY groups, in any of the markers for diabetes. In conclusion, curcumin mixed into yoghurt at the highest dose tested exhibited anti-diabetic activity, improving significantly most of the markers assessed in this study.
\end{abstract}

Key words: Functional food: Glycaemia: Proteinuria: Body weight

Diabetes mellitus (DM) is a group of metabolic disorders characterised by high levels of glucose in the blood (hyperglycaemia), arising from deficient secretion and/or inefficient action of the hormone insulin, which leads to changes in the metabolism of carbohydrates, lipids and proteins. Apart from hyperglycaemia, these changes typically result in: loss of weight, despite the increased hunger inducing a higher rate of eating, increased water intake and urinary volume, glycosuria, proteinuria and a raised level of urinary urea ${ }^{(1)}$.

A recent study on the prevalence of DM among adults (aged 20-79 years) in ninety-one countries showed that it would affect 285 million adults $(6 \cdot 4 \%)$ in 2010 and this would increase to 439 million $(7 \cdot 7 \%)$ by 2030 . This study also showed that, between 2010 and 2030, the numbers of adults in developing countries with DM will rise by $69 \%$, while in developed countries the increase will be $20 \%{ }^{(2)}$.
Current developments in pharmaceutical technology are directed not only at the discovery of new drugs, but also at new ways of administering them. Around the world, there is a trend towards the use of functional foods, namely items of food that afford physiological or metabolic health benefits, besides their ordinary nutritional value ${ }^{(3)}$. Yoghurt is a popular, tasty and healthy milk product, produced and consumed in ever-growing amounts on account of its organoleptic qualities and high nutritional value when used as a food supplement ${ }^{(4)}$. Moreover, yoghurt supplemented with natural pigments has been used experimentally in vitro in the study of diabetes and hypertension management ${ }^{(5)}$.

Curcumin, a natural yellow pigment isolated from the edible rhizome of the tropical South Asian herbaceous plant turmeric (Curcuma longa L.), of the ginger family, is known to possess antioxidant, anti-inflammatory, anticancer and antibacterial

Abbreviations: ALP, alkaline phosphatase; ALT, alanine aminotransferase; AST, aspartate aminotransferase; BW, body weight; DC30, diabetic rats treated with curcumin $(30 \mathrm{mg} / \mathrm{kg}$ body weight); DC60, diabetic rats treated with curcumin ( $60 \mathrm{mg} / \mathrm{kg}$ body weight); DC 90 , diabetic rats treated with curcumin $(90 \mathrm{mg} / \mathrm{kg}$ body weight); DI, diabetic rats treated with insulin (4U); DM, diabetes mellitus; DW, diabetic rats treated with water; DY, diabetic rats treated with yoghurt; ND, non-diabetic; NDC90, non-diabetic rats treated with curcumin ( $90 \mathrm{mg} / \mathrm{kg}$ body weight); NDW, non-diabetic rats treated with water; NDY, non-diabetic rats treated with yoghurt; STZ, streptozotocin.

* Corresponding author: Professor I. L. Brunetti, fax +55 xx01633220075, email brunetti@fcfar.unesp.br 
properties. Thus, it has been employed in the treatment of some disorders, such as Alzheimer's disease, gastric ulcer, psoriasis and diabetes ${ }^{(6)}$.

Published experiments in which an ethanolic solution or aqueous suspension of curcumin was administered to diabetic animals have demonstrated a lowering of the glycaemia $^{(7,8)}$. Reduction of the serum activity of aspartate aminotransferase (AST) and alanine aminotransferase (ALT) and of serum levels of cholesterol and $\mathrm{TAG}^{(8-10)}$ and a gain in body weight $(\mathrm{BW})^{(11)}$ have also been observed after treatment of diabetic rats and mice with curcumin. Furthermore, it was found that treatment with curcumin or turmeric powder delays cataract in diabetic rats by preventing hyperglycaemia-induced lenticular oxidative stress, aggregation and insolubilisation of lens proteins ${ }^{(12)}$. Chronic treatment with a suspension of curcumin in carboxymethylcellulose significantly attenuated renal dysfunction in diabetic rats, indicated by the levels of polyuria, proteinuria, serum creatinine, blood urea nitrogen and creatinine and urea clearance ${ }^{(13)}$. Corroborating these data, it has been shown that renal lesions can be reduced in streptozotocin (STZ)-diabetic rats by means of a diet supplemented with curcumin. The improvement was demonstrated by the amount of protein excreted in the urine and the extent of leaching of tubular enzyme, the measured activities of several key enzymes in the renal tissue and histological examination of kidney sections ${ }^{(14)}$

This pigment is used in many food products and dishes, especially those spiced with turmeric, such as curry and yellow rice ${ }^{(15,16)}$. No study has yet reported any toxic effects associated with ingestion of curcumin, in animals ${ }^{(17)}$ or in humans, even at very high doses ${ }^{(18)}$. In spite of the considerable benefits offered by curcumin, the development of efficacious clinical forms of this pigment remains a great challenge, owing to its very low bioavailability when taken orally ${ }^{(19)}$.

A number of vehicles are being investigated, including nanoparticles $^{(20)}$, liposomes ${ }^{(21)}$ and complexes with phospholipids $^{(22)}$, as well as the addition of adjuvants such as piperine ${ }^{(23)}$, but it is well worth trying other formulations in which curcumin may show improvements in bioavailability. Few studies have been published on the supplementation of yoghurt with natural pigments, and to the best of our knowledge none has been carried out in which in vivo assays were used to treat diabetes with curcumin. We therefore prepared mixtures of natural milk yoghurt with various concentrations of curcumin and assessed their effects on the classical symptoms of experimental diabetes.

\section{Materials and methods}

\section{Animals}

A total of forty-eight male Wistar rats of BW 120 (SEM 5) g (diabetic groups) and twenty-four rats of BW 180 (SEM 5) g (non-diabetic (ND) groups), were obtained from the central animal facility of the Unesp campus at Botucatu, SP, Brazil. Each animal was housed in a separate metabolic cage, under a $12 \mathrm{~h}$ light$12 \mathrm{~h}$ dark cycle, at a constant temperature of $23 \pm 1{ }^{\circ} \mathrm{C}$ and relative humidity of $55 \pm 5 \%$, and had free access to water and commercial rat feed (Purina ${ }^{\circledR}$ - Evialis do Brasil Nutrição Animal Ltda., Paulínia, SP, Brazil), throughout the 31-d experiment. The study was conducted in compliance with all relevant recommendations of Colégio Brasileiro de Experimentação Animal on the care and use of animals, and all experimental procedures involving animals received prior approval by the School Research Ethics Committee (Faculdade de Ciências Farmacêuticas/Unesp at Araraquara: resolution 11/2008).

\section{Induction of diabetes}

After a period of adaptation, the rats were fasted for $14-16 \mathrm{~h}$. Following this, the forty-eight animals referred to earlier were given an injection (intravenous) of $40 \mathrm{mg}$ per $\mathrm{kg}$ BW of STZ (catalogue no. S0130; Sigma Aldrich, St Louis, MO, USA) dissolved in $10 \mathrm{~mm}$-citrate buffer ( $\mathrm{pH} \mathrm{4.5)}$ to induce diabetes, while the remaining twenty-four animals received a similar injection of the buffer. And $4 \mathrm{~d}$ later, the blood glucose level of STZ-treated rats had risen to $27-28 \mathrm{mmol} / 1$, while that of the twenty-four ND rats remained around $7 \cdot 8 \mathrm{mmol} / 1$.

\section{Prolonged treatment with curcumin}

Curcumin (catalogue no. 28260; Sigma Aldrich-Fluka, St Louis, MO, USA) was mixed with plain yoghurt (Nestlé, Araras, SP, Brazil), in appropriate proportions, with a homogeniser (Metabo, Marconi, Piracicaba, SP, Brazil) operating at $27000 \mathrm{rpm}$ for $90 \mathrm{~s}$, at a controlled ambient temperature of $25^{\circ} \mathrm{C}$. The treatment started $4 \mathrm{~d}$ after the STZ injection, the rats having been placed in nine treatment groups of eight animals/ group that were balanced in glycaemia and BW. The groups were treated as follows: diabetic rats were given water (group DW), plain yoghurt (DY), curcumin in yoghurt at $30 \mathrm{mg}$ (DC30), $60 \mathrm{mg}$ (DC60) or $90 \mathrm{mg} / \mathrm{kg} \mathrm{BW}$ per d (DC90) or insulin (DI); ND rats were: treated with water (NDW), given yoghurt (NDY) or curcumin in yoghurt at $90 \mathrm{mg} / \mathrm{kg}$ BW per d (NDC90).

All rats were treated twice a day by gavage (except group DI), at 08.00 and 18.00 hours, for $31 \mathrm{~d}$. Rats in the experimental control groups (DW, NDW, DY and NDY) were given $1.0 \mathrm{ml} / \mathrm{d}$ of water or yoghurt, while group DI received subcutaneous injections of $13.89 \mu \mathrm{mol} / \mathrm{rat}$ of insulin (Biohulin NU-100; 100 units/ml; Biobrás, Monte Claro, MG, Brazil) in $0.3 \mathrm{ml}$ physiological saline, totalling $27.78 \mu \mathrm{mol} /$ rat per $\mathrm{d}$ in $0.6 \mathrm{ml}$. The curcumin-treated groups received 15 (DC30), 30 (DC60) or 45 (DC90 and NDC90) $\mathrm{mg} / \mathrm{kg}$ BW of the pigment in $0.5 \mathrm{ml} \mathrm{yog}$ hurt, totalling $1.0 \mathrm{ml} / \mathrm{rat} / \mathrm{d}$ of curcumin-supplemented yoghurt.

At the end of the treatment, the rats were killed by decapitation, blood was collected for analysis and the extensor digitorum longus and soleus muscles and the retroperitoneal and epididymal fat pads were immediately removed from each animal and weighed, as was a piece of the liver, to assay its glycogen content in $\mathrm{g} / 100 \mathrm{~g}$ liver tissue ( $\mathrm{g} \%$ ).

\section{Chemical analysis}

Blood glucose was determined by using glucose oxidase and peroxide-mediated oxidative coupling of $p$-aminophenazone to phenol, catalysed by peroxidase ${ }^{(24)}$. Serum levels of ALT 
and AST activities were assayed with continuous-monitoring methods ${ }^{(25)}$ by coupling transaminase reactions to specific dehydrogenase reactions, in which the oxo-acids formed in the transaminase reactions, are measured in an enzymatic reduction to the corresponding hydroxy acids, with the oxidation of $\mathrm{NADH}$. The serum level of the alkaline phosphatase (ALP) activity was determined with the 'self-indicating' substrate, $p$-nitrophenylphosphate, and a phosphate-accepting buffer, in a continuous-monitoring method ${ }^{(26)}$. Serum concentration of total cholesterol was determined by coupling the enzymatic reactions of cholesteryl ester hydrolase and cholesterol oxidase, where $\mathrm{H}_{2} \mathrm{O}_{2}$ is one of the products of the oxidase reaction and is measured in a peroxidase-catalysed reaction that forms a quinoneimine dye ${ }^{(27)}$. The homogeneous assay used for HDL-cholesterol was based on the accelerator selective detergent method, where a synthetic polymer is used together with a polyanion to block the non-HDL; a detergent is then added that exposes only the cholesterol in HDL to the enzymes: cholesteryl ester hydrolase, cholesterol oxidase and peroxidase ${ }^{(27,28)}$. TAG was determined by sequential enzymatic reactions of a lipase, glycerokinase and glycerolphosphate oxidase; in the oxidase reaction, the $\mathrm{H}_{2} \mathrm{O}_{2}$ generated is measured by a coupled oxidative reaction of 4-aminoantipyrine and 4-chlorophenol, catalysed by peroxidase, yielding a quinoneimine dye ${ }^{(27)}$. All the aforementioned assays were spectrophotometric and carried out in a LabMax240 autoanalyser (Labtest-Chuo-Ku, Tokyo, Japan). Urinary protein was determined by the Bradford method ${ }^{(29)}$, which is based on the binding of the Coomassie dye to proteins, with the formation of a coloured complex monitored at $570-600 \mathrm{~nm}$. The urea was assayed by the urease method, in which urinary urea is hydrolysed by urease to $\mathrm{NH}_{3}$, which in turn is assayed by measuring NADH at $340 \mathrm{~nm}$, consumed in the presence of glutamate dehydrogenase ${ }^{(30)}$. The o-toluidine method ${ }^{(31)}$ was used for glycosuria; this aromatic amine condenses with the aldehyde group of glucose to produce a green chromophore, monitored at $630 \mathrm{~nm}$. The anthrone method ${ }^{(32)}$ was used for hepatic glycogen, in which the hepatic glycogen is extracted with $30 \% \mathrm{KOH}$ and then precipitated with alcohol and the quantity of pellet recovered is determined (in triplicate) by the reaction with anthrone (9,10-dihydro-9-oxoanthracene), where a coloured product is formed with reducing sugars and can be monitored at $620 \mathrm{~nm}$.

Except when indicated, the absorbance was read in a Femto Plus 600 spectrophotometer (Femto Indústria e Comércio de Instrumentos Ltda., São Paulo, SP, Brazil) and all kits were obtained from Labtest Diagnóstica S.A. (Lagoa Santa, MG, Brazil). Other reagents were purchased from Merck (Darmsradt, Germany) or Sigma and were of at least analytical grade.

\section{Statistical analysis}

The results are expressed as means with their standard errors. Differences were assessed by ANOVA - one-way for the analyses: cholesterol, HDL-cholesterol, TAG, hepatic glycogen, food intake, water intake, urine volume, extensor digitorum longus muscle, soleus muscle, retroperitoneal fat and epididymal fat; or two-way for repeated measures, with groups and time as the factors, for the analyses: BW, glucose, glycosuria, proteinuria, urinary urea, AST, ALT and ALP; followed by the Student-Newman-Keuls test, using the program Sigma Stat 3.5 (Systat Software, Inc., San Jose, CA, USA). Significance was accepted when $P<0 \cdot 05$.

\section{Results}

In the present study, we investigated the effect of feeding curcumin, suspended in plain yoghurt at various concentrations, to diabetic and ND rats. Over a period of $31 \mathrm{~d}$, the supplemented yoghurt was given to the rats by gavage each morning and evening, while the main physiological and biochemical variables that often change in diabetic animals were analysed. To maximise the reliability of the experiment, the animals were matched, $4 \mathrm{~d}$ after induction of DM with STZ, with respect to BW and glycaemia, so that the three groups of ND rats started with the same mean values of glycaemia and weight, and the six groups of diabetic rats with the same mean weight and severity of diabetes (Table 1).

It can be seen in Fig. 1 that group DI consistently gained more weight than any other diabetic group, followed by DC90. There were significant differences between DI and DW, DY and DC30, from day $21(P<0 \cdot 05)$, as well as between DC90 and DW, DY and DC30 $(P<0.05)$. Overall, DI showed a weight gain of $137.25 \mathrm{~g}$ and DC90 a gain of $108.37 \mathrm{~g}$, whereas groups DW and DY grew little, gaining only $42.66 \mathrm{~g}$ and $38.75 \mathrm{~g}$, respectively. Comparison of mean weights of the same groups at different times shows that groups DI, DC30, DC60 and DC90 increased significantly from their initial values from day 7 of the treatment, while groups DW and DY changed significantly from their initial values only from day 14 of the treatment.

The blood glucose levels (Fig. 2) in group DI fell to around $10.0 \mathrm{mmol} / 1$, where they remained steady until the end of the experiment. The levels of glucose were also reduced in DC90, to 18.43 (SEM 1.40) $\mathrm{mmol} / \mathrm{l}$, and in DC60, to 23.01 (SEM $2 \cdot 22) \mathrm{mmol} / \mathrm{l}$. The control groups, DW and DY, showed rising glucose levels throughout the experiment, reaching 34.46 and $31.46 \mathrm{mmol} / 1$, respectively. None of the three groups of ND animals (NDW, NDY and NDC90) suffered any significant change in glucose levels relative to each other or to their initial levels.

The concentration of urinary glucose (Fig. 3) shows a significant fall in group DI on day 7 , in contrast to all other diabetic groups, and remains at this level until the end. In group DC90, the level rose more slowly than in DW and DY, and became significantly lower than these controls from day 14 of the treatment. Comparing the levels at different times for the same group (intragroup comparison), we find that groups DW, DY and DC30 showed a significant rise from day 7 of the treatment. However, DC90 and DI did not show any significant change from day 0 .

The results obtained for proteinuria (Fig. 4) show that, on day 0 , the apparent differences among the diabetic groups are not significant, nor are they among the ND groups. On day 7 , however, the level of group DI was significantly lower than those of DW, DY, DC30, DC60 and DC90, and remained so until the end of the experiment. On day 14, group DI attained a value of proteinuria similar to that of 
Table 1. Biochemical and physiological variables of the diabetic and non-diabetic rats during treatment with curcumin (Mean values with their standard errors $(n 8)$ )

\begin{tabular}{|c|c|c|c|c|c|c|c|c|c|c|c|c|c|c|c|c|c|c|}
\hline \multirow[b]{3}{*}{ Parameters } & \multicolumn{18}{|c|}{ Groups } \\
\hline & \multicolumn{2}{|c|}{ DW } & \multicolumn{2}{|c|}{ DY } & \multicolumn{2}{|c|}{ DC30 } & \multicolumn{2}{|c|}{ DC60 } & \multicolumn{2}{|c|}{ DC90 } & \multicolumn{2}{|l|}{$\mathrm{DI}$} & \multicolumn{2}{|c|}{ NDW } & \multicolumn{2}{|l|}{ NDY } & \multicolumn{2}{|c|}{ NDC90 } \\
\hline & Mean & SEM & Mean & SEM & Mean & SEM & Mean & SEM & Mean & SEM & Mean & SEM & Mean & SEM & Mean & SEM & Mean & SEM \\
\hline BW (g)ๆ ๆ & $158 \cdot 56$ & 4.50 & $165 \cdot 18$ & $3 \cdot 10$ & $163 \cdot 68$ & 4.60 & $160 \cdot 93$ & 5.90 & $160 \cdot 31$ & 3.53 & $163 \cdot 12$ & 4.47 & $236 \cdot 06$ & $3 \cdot 10$ & $233 \cdot 37$ & 4.59 & 233.00 & 7.04 \\
\hline Glucose $(\mathrm{mmol} / \mathrm{l})$ ๆ ๆ & 28.05 & 1.04 & 27.53 & $1 \cdot 24$ & 28.69 & 1.35 & 27.85 & $2 \cdot 25$ & $27 \cdot 80$ & 1.24 & $28 \cdot 18$ & 1.36 & 7.80 & 0.26 & 7.79 & 0.24 & 7.86 & 0.15 \\
\hline Cholesterol $(\mathrm{mmol} / \mathrm{l} /)^{\star \star \star}$ & $2 \cdot 27$ & 0.10 & $2 \cdot 19$ & 0.07 & $2 \cdot 11$ & 0.20 & 2.08 & 0.15 & 1.97 & 0.10 & $1.50 \S$ & 0.10 & 1.99 & 0.04 & $2 \cdot 00$ & 0.09 & 1.95 & 0.06 \\
\hline HDL-cholesterol $(\mathrm{mmo} / /)^{\star \star \star \star}$ & $1 \cdot 11$ & 0.07 & 1.05 & 0.04 & 1.05 & 0.05 & 1.04 & 0.12 & 1.01 & 0.11 & 0.92 & 0.03 & 1.05 & 0.95 & 1.07 & 0.03 & 1.08 & 0.07 \\
\hline TAG $(\mathrm{mmol} / /)^{* \star \star}$ & 4.53 & 0.82 & 4.06 & 0.78 & 4.03 & 0.92 & 3.41 & 0.60 & $2.56 \pi$ & 0.52 & $1.57 \ddagger$ & 0.18 & $1.02 \ddagger$ & 0.28 & $1.04 \ddagger$ & 0.22 & $1.03 \ddagger$ & 0.23 \\
\hline Hepatic glycogen $(\mathrm{g} \%)^{\star \star \star}$ & 2.07 & 0.17 & $2 \cdot 15$ & 0.30 & 2.35 & 0.39 & 2.39 & 0.34 & $2 \cdot 82^{*}$ & 0.33 & $4.01+t$ & 0.33 & 4.13+t & 0.53 & $4 \cdot 12+t$ & 1.02 & $4.02+\dagger$ & $1 \cdot 19$ \\
\hline Food intake (g/24h $100 \mathrm{~g} \mathrm{BW})+\dagger \dagger$ & $19 \cdot 36$ & 0.77 & $20 \cdot 18$ & 0.77 & 19.98 & 0.79 & $16 \cdot 87$ & 0.83 & 14.91\| & 0.43 & $12 \cdot 25 \ddagger \ddagger$ & 0.44 & $10 \cdot 33\|\| \|$ & 0.19 & $9 \cdot 77\|\| \|$ & 0.14 & $10 \cdot 46\|\| \|$ & 0.16 \\
\hline Water intake $(\mathrm{ml} / 24 \mathrm{~h} 100 \mathrm{~g} \mathrm{BW})+\dagger \dagger$ & 83.05 & 4.49 & 69.58 & 6.23 & 83.89 & 3.96 & 56.97 & $3 \cdot 10$ & $51.51 \|$ & 2.01 & $17 \cdot 38 \neq \ddagger$ & $1 \cdot 10$ & $14 \cdot 15\|\| \mid$ & 0.49 & $12 \cdot 10\|\| \|$ & 0.33 & 12.69\|\|$\|$ & 0.44 \\
\hline Urine volume $(\mathrm{ml} / 24 \mathrm{~h} 100 \mathrm{~g} \mathrm{BW})+\dagger \dagger$ & 63.91 & 5.31 & $65 \cdot 37$ & 2.56 & 63.08 & 2.59 & $57 \cdot 36$ & 3.08 & $38.79^{\star *}$ & 1.32 & $13.07 \ddagger \ddagger$ & 1.83 & 8.41\|\|$\|$ & 0.09 & 8.39\|\|$\|$ & 0.10 & 8.40\|\| & 0.10 \\
\hline EDL muscle $(\mathrm{g})^{\star \star \star}$ & 0.084 & 0.008 & 0.083 & 0.008 & 0.086 & 0.014 & 0.087 & 0.002 & 0.100 & 0.007 & $0.133 \dagger$ & 0.011 & $0.152 \S \S$ & 0.008 & $0.161 \S \S$ & 0.005 & $0.146 \S \S$ & 0.005 \\
\hline Soleus muscle $(\mathrm{g})^{\star \star \star *}$ & 0.091 & 0.005 & 0.093 & 0.003 & 0.094 & 0.010 & 0.096 & 0.007 & 0.107 & 0.010 & $0.128 \dagger$ & 0.008 & $0.139 \S \S$ & 0.007 & $0.154 \S \S$ & 0.005 & $0.142 \S \S$ & 0.006 \\
\hline Retroperitoneal fat $(\mathrm{g})^{\star \star \star \star}$ & 0.11 & 0.05 & 0.11 & 0.02 & 0.18 & 0.13 & 0.23 & 0.19 & 0.46 & 0.09 & $1.00 \ddagger$ & 0.31 & $1.15 \ddagger$ & 0.10 & $1 \cdot 10 \ddagger$ & 0.10 & $1 \cdot 13 \ddagger$ & 0.08 \\
\hline Epididymal fat $(\mathrm{g})^{\star \star \star}$ & 0.42 & 0.09 & 0.44 & 0.07 & 0.48 & 0.03 & 0.49 & 0.12 & 0.67 & 0.07 & $1.41 \neq \ddagger$ & 0.24 & $2.05 \S \S$ & 0.14 & $1.93 \S \S$ & 0.14 & $1.96 \S \S$ & 0.10 \\
\hline
\end{tabular}

DW, diabetic rats treated with water; DY, diabetic rats treated with yoghurt; DC30, diabetic rats treated with curcumin (30 mg/kg body weight (BW)); DC60, diabetic rats treated with curcumin (60 mg/kg BW); DC90, diabetic rats treated with curcumin $(90 \mathrm{mg} / \mathrm{kg} \mathrm{BW})$; DI, diabetic rats treated with insulin $(27.78 \mu \mathrm{mol})$; NDW, non-diabetic rats treated with water; NDY, non-diabetic rats treated with yoghurt; NDC90, non-diabetic rats treated with curcumin

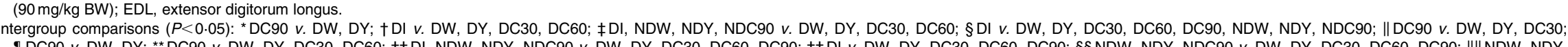

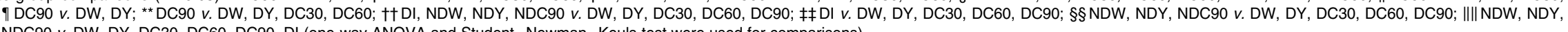
NDC90 v. DW, DY, DC30, DC60, DC90, DI (one-way ANOVA and Student-Newman-Keuls test were used for comparisons).

${ }_{* \star \star *}$ Measured on day 31 of treatment (killing)

tt†Results pooled from day 7 to day 31 of treatment. 


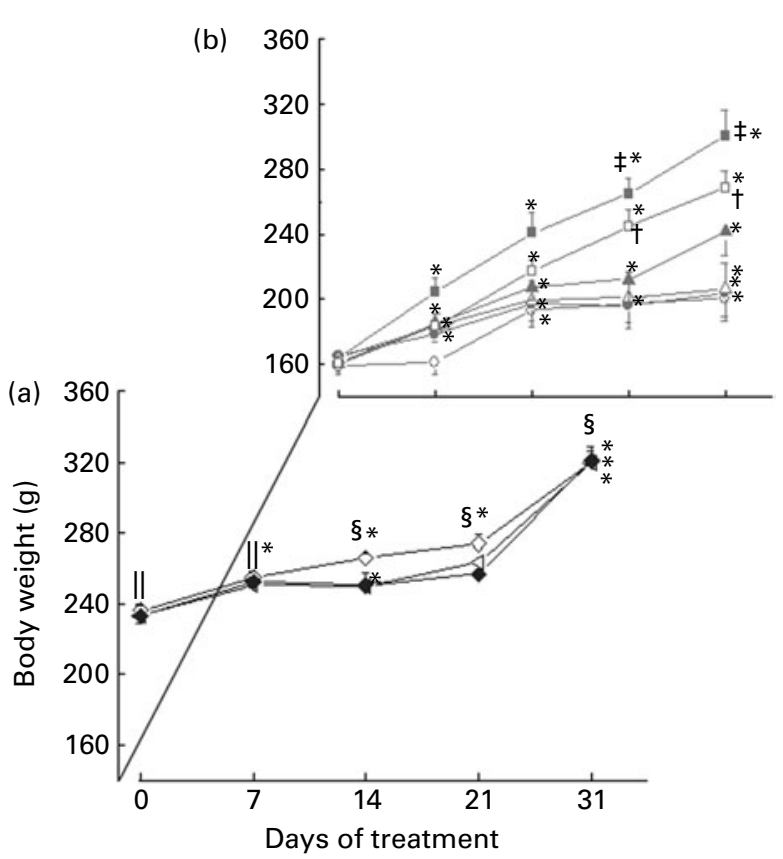

Fig. 1. Effect of prolonged treatment of diabetic rats with curcumin on body weight (BW, g). Values are group means with their standard errors ( $n$ 8). (a) Non-diabetic rats treated with water (NDW, $\checkmark$ ); non-diabetic rats treated with yoghurt (NDY, — $\longrightarrow$ ); non-diabetic rats treated with curcumin (90 mg/kg BW) (NDC90, \ـ). (b) Diabetic rats treated with water (DW, $-\mathrm{O}-$ ); diabetic rats treated with yoghurt (DY, - $\longrightarrow$ ); diabetic rats treated with curcumin $(30 \mathrm{mg} / \mathrm{kg} \mathrm{BW})(\mathrm{DC} 30,-\triangle)$; diabetic rats treated with curcumin $(60 \mathrm{mg} / \mathrm{kg} \mathrm{BW})(\mathrm{DC} 60, \ldots$ ); diabetic rats treated with curcumin $(90 \mathrm{mg} / \mathrm{kg} \mathrm{BW})(\mathrm{DC} 90,-\square-)$; diabetic rats treated with insulin $(27.78 \mu \mathrm{mol})$ (DI, —- Repeated-measures ANOVA and Student-Newman-Keuls test were used for comparisons. Intergroup comparisons $(P<0.05)$ : †DC90 v. DW, DY, DC30; ‡DI v. DW, DY, DC30; §NDW, NDY, NDC90 v. DW, DY, DC30, DC60; || NDW, NDY, NDC90 v. DW, DY, DC30, DC60, DC90, DI. Intragroup comparisons: ${ }^{*} P<0.05$; with day 0 .

the ND groups, where it remained until day 31. In relation to group DC90 on day 7, its proteinuria was significantly lower than that of DW and DY and remained so until the end of the experiment. On the last day, group DI showed a proteinuria about $82.4 \%$ lower than the diabetic control groups, DW and DY, while group DC90 showed a fall of about $48.0 \%$ relative to the controls. Moreover, DW and DI were the only groups that exhibited any levels significantly different from those on day 0 . The profiles of the three groups of ND animals were similar to each other and their proteinuria was lower than those of all the diabetic groups except DI.

For urinary urea (Fig. 5), the insulin-treated rats showed a significant fall on day 7 , in contrast to all other groups, and remained at this level until the end. Moreover, significant differences were observed between group DI and groups DW, DY, DC30, DC60 and DC90 from day 7, and also between DC90 and group DW, which were maintained until the last day. DC90 fell significantly relative to DY from day 14 to the end of treatment. In the intragroup comparison, it was found that DW, DY, DC30 and DC60 showed significantly changed levels from day 7 , which remained so until the end. The urinary urea levels in all the ND groups, on day 0 and day 7 , were significantly lower than in all the diabetic groups. This was also true during the rest of the treatment, except in the case of group DI, which had a level similar to the ND groups.
With respect to daily food intake, water intake and urine volume and the weights of the extensor digitorum longus and soleus muscles and retroperitoneal and epididymal fat pads, for all the diabetic groups, during treatment and/or on day 31 (Table 1), we can see that group DI was significantly different from groups DW, DY and DC30 in all seven of these variables. DC90 showed a significant difference from the groups DW and DY, for all the variables except the weights of muscles and fat pads. Groups DC60 and DC30 suffered no significant change in any variable. It should also be noted that the curcumin-treated groups showed dose-dependent increases in the masses of both fat pads, relative to those of DW and DY, though significance was not proved.

It is seen that the mean TAG level of group DC60 was reduced by $1.12 \mathrm{mmol} / \mathrm{l}$ and that of DC90 by $1.97 \mathrm{mmol} / \mathrm{l}$, relative to group DW (Table 1 ). DI showed a greater reduction in TAG $(2.96 \mathrm{mmol} / \mathrm{l})$, but remained at a level about $0.54 \mathrm{mmol} / \mathrm{l}$ higher than those of the ND rats. In terms of total cholesterol, group DI was significantly different from DW, DY, DC30, DC60 and DC90, while the HDL-cholesterol level was not significantly different between any of the groups (Table 1). The hepatic glycogen content was very similar in all the ND rats and group DI, and these levels were significantly higher than those in all the non-DI $(P<0.05)$.

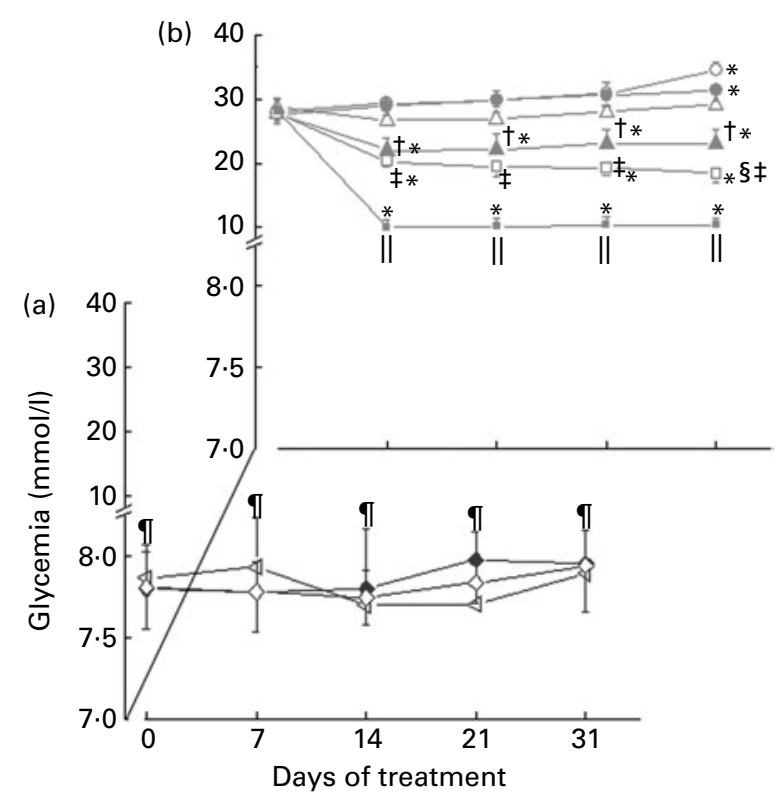

Fig. 2. Effect of prolonged treatment of diabetic rats with curcumin on glycaemia $(\mathrm{mmol} / \mathrm{l})$. Values are group means with their standard errors $(n 8)$. (a) Non-diabetic rats treated with water (NDW, $\prec$ ); non-diabetic rats treated with yoghurt (NDY, —-); non-diabetic rats treated with curcumin $(90 \mathrm{mg} / \mathrm{kg}$ body weight (BW)) (NDC90, \ـ). (b) Diabetic rats treated with water (DW, - - - ) ; diabetic rats treated with yoghurt (DY, $\longrightarrow-$ ); diabetic rats treated with curcumin $(30 \mathrm{mg} / \mathrm{kg} \mathrm{BW})(\mathrm{DC} 30,-\triangle-)$; diabetic rats treated with curcumin $(60 \mathrm{mg} / \mathrm{kg} \mathrm{BW})(\mathrm{DC} 60, \longrightarrow$ ); diabetic rats treated with curcumin $(90 \mathrm{mg} / \mathrm{kg} \mathrm{BW})(\mathrm{DC} 90,-\square-)$; diabetic rats treated with insulin $(27.78 \mu \mathrm{mol})$ (DI, - - Repeated-measures ANOVA and StudentNewman-Keuls test were used for comparisons. Intergroup comparisons $(P<0.05)$ : †DC60 v. DW, DY; ‡DC90 v. DW, DY; §DC90 v. DC30; \|DI v. DW, DY, DC30, DC60, DC90; I NDW, NDY, NDC90 v. DW, DY, DC30, DC60, DC90, DI. Intragroup comparisons: ${ }^{\star} P<0.05$; with day 0 . 


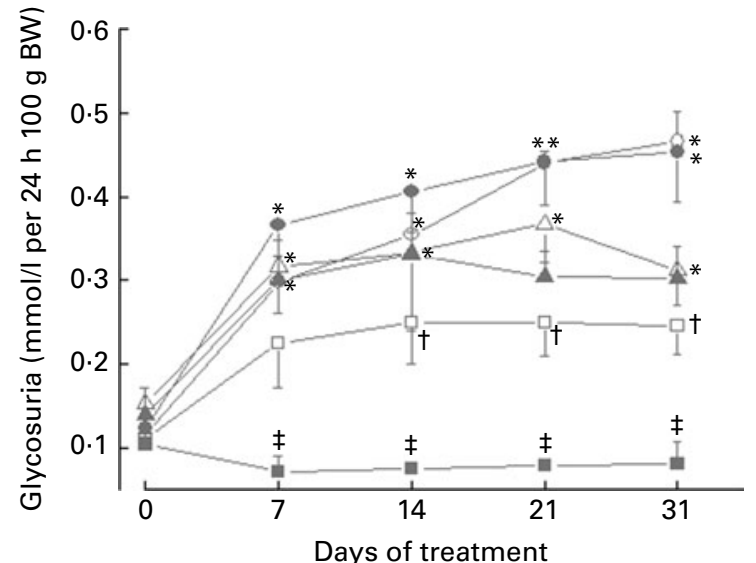

Fig. 3. Effect of prolonged treatment of diabetic rats with curcumin on glucosuria (mmol// per $24 \mathrm{~h} 100 \mathrm{~g}$ body weight $(\mathrm{BW}))$. Values are group means with their standard errors ( $n$ 8). Diabetic rats treated with water (DW, $-0-$ ); diabetic rats treated with yoghurt (DY, —-); diabetic rats treated with curcumin $(30 \mathrm{mg} / \mathrm{kg} \mathrm{BW})(\mathrm{DC} 30,-\triangle)$; diabetic rats treated with curcumin $(60 \mathrm{mg} / \mathrm{kg} \mathrm{BW})(\mathrm{DC} 60, \longrightarrow$ ); diabetic rats treated with curcumin $(90 \mathrm{mg} / \mathrm{kg}$ BW) (DC90, - —); diabetic rats treated with insulin $(27.78 \mu \mathrm{mol})$ (DI, - - Repeated-measures ANOVA and Student-Newman-Keuls test were used for comparisons. Intergroup comparisons $(P<0.05)$ : †DC90 $v$. DW, DY; $\ddagger \mathrm{DI} v$. DW, DY, DC30, DC60, DC90. Intragroup comparisons: ${ }^{*} P<0.05$; with day 0 .

However, one of the non-DI, DC90, had significantly more hepatic glycogen $(P<0.05)$ than DW and DY.

In relation to enzymes, we observe that all the diabetic groups showed a great rise in AST activity during the $31 \mathrm{~d}$, although this rise is significantly less in groups DI and DC90 than in DW and DY (Table 2). For ALT, there was a significant rise in activity $(P<0.05)$ in all groups during the experiment, except in the case of DI, where the rise was much smaller. Both AST and ALT activities are reduced in a dose-dependent manner in the curcumin-treated groups, relative to DW and DY, and this reduction is significant in DC60 and DC90, for ALT. In the intragroup analysis for the transaminases, we find a significant increase in ALT in all the diabetic groups except DI.

In the case of serum ALP, no significant difference was revealed between the levels before and after treatment, in any group. However, in group DC90, the activity was significantly lower than in groups DW and DY, at the end of treatment, while DI showed a significantly lower activity than all other diabetic groups at that time.

It is to be also noted that comparisons between the ND controls and group NDC90 failed to reveal any statistical difference, in any of the results for the serum enzyme activities. While the activities of AST and ALT in the ND groups were significantly lower than in the diabetic groups on day 31, the same pattern was observed for ALP activity, except in group DI.

\section{Discussion}

The results reported in the previous section suggest that the STZ injected was strongly cytotoxic to the pancreatic $\beta$-cells, since it provoked all the classical alterations in physiological and biochemical markers expected in experimental diabetes, namely, hyperglycaemia, polydipsia, weight loss, polyphagia, polyuria, glycosuria, proteinuria and raised urinary urea levels ${ }^{(33)}$. Such results have already been described by our laboratory, including the histological changes in various tissues ${ }^{(34)}$.

Weight loss or poor growth in diabetic animals arises from the breakdown of structural proteins and body fat ${ }^{(35)}$ due to the lack of insulin. Insulin inhibits the hormone-sensitive lipase, preventing the occurrence of excessive lipolysis, and also promotes glucose uptake by adipose tissue, favouring lipogenesis ${ }^{(36)}$. These factors result in a gain in BW when the animal is treated with an efficient hypoglycaemic agent, which occurred in the groups DI and DC90 (Fig. 1). It is also worth noting that the treated diabetic groups DI, DC60 and DC90 started to gain weight a week earlier than the control groups DW and DY.

In diabetic rats treated with curcumin $(30,60,90 \mathrm{mg} / \mathrm{kg}$ BW per d), we observed a fall in blood glucose (Fig. 2), as also food and water consumption, and a rise in BW (Table 1). This fall in glycaemia may in part be explained by the stimulation of insulin secretion by curcumin, since an increase of this hormone in the plasma has been reported in animals treated with $0 \cdot 2 \mathrm{~g} / \mathrm{kg}$ BW of curcumin ${ }^{(11)}$. Thus, it can be suggested that the $\beta$-cells are partially destroyed by STZ and that the surviving endocrine cells would continue

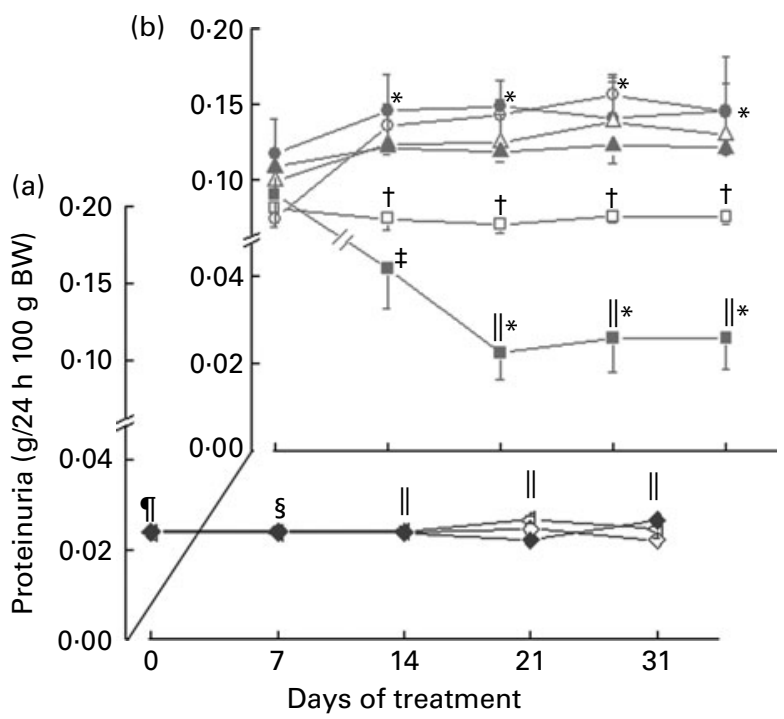

Fig. 4. Effect of prolonged treatment of diabetic rats with curcumin on proteinuria $(\mathrm{g} / 24 \mathrm{~h} 100 \mathrm{~g}$ body weight $(\mathrm{BW}))$. Values are group means with their standard errors ( $n$ 8). (a) Non-diabetic rats treated with water (NDW, $\checkmark$ ); non-diabetic rats treated with yoghurt (NDY, — $\longrightarrow$ ); non-diabetic rats treated with curcumin $(90 \mathrm{mg} / \mathrm{kg}$ body weight (BW)) (NDC90, ——). (b) Diabetic rats treated with water (DW, - - -); diabetic rats treated with yoghurt (DY, —- ); diabetic rats treated with curcumin $(30 \mathrm{mg} / \mathrm{kg} \mathrm{BW})$ (DC30, $\longrightarrow$ ); diabetic rats treated with curcumin $(60 \mathrm{mg} / \mathrm{kg} \mathrm{BW})$ (DC60, - ); diabetic rats treated with curcumin $(90 \mathrm{mg} / \mathrm{kg} \mathrm{BW})(\mathrm{DC} 90,-\square-$ ); diabetic rats treated with insulin $(27.78 \mu \mathrm{mol})$ (DI, - - Repeatedmeasures ANOVA and Student-Newman-Keuls test were used for comparisons. Intergroup comparisons $(P<0.05)$ : †DC90 v. DW, DY; †DI $v$. DW, DY, DC30, DC60, DC90; §NDW, NDY, NDC90 v. DW, DY, DC30, DC60, DC90; ॥NDW, NDY, NDC90, DI v. DW, DY, DC30, DC60, DC90; ๆ NDW, NDY, NDC90 v. DW, DY, DC30, DC60, DC90, DI. Intragroup comparisons: ${ }^{*} P<0.05$; with day 0 . 


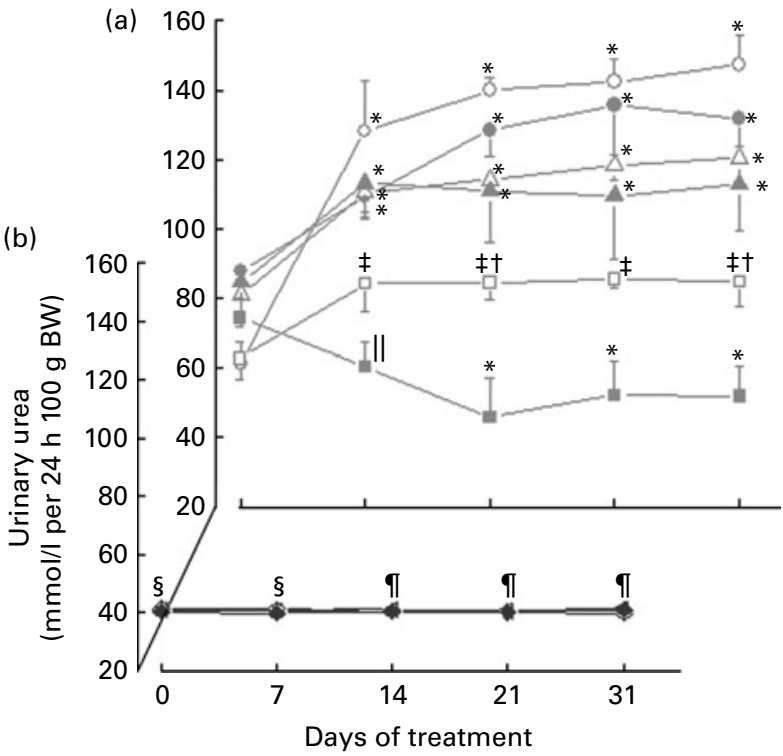

Fig. 5. Effect of prolonged treatment of diabetic rats with curcumin on urinary urea $(\mathrm{mmol} / \mathrm{l}$ per $24 \mathrm{~h} 100 \mathrm{~g}$ body weight $(B W))$. Values are group means with their standard errors $(n 8)$. (a) Non-diabetic rats treated with water (NDW, $\checkmark$ ); non-diabetic rats treated with yoghurt (NDY, $\multimap$ ); non-diabetic rats treated with curcumin $(90 \mathrm{mg} / \mathrm{kg}$ body weight (BW)) (NDC90, $\smile$-). (b) Diabetic rats treated with water (DW, $-\mathrm{O}-$ ); diabetic rats treated with yoghurt (DY, —-); diabetic rats treated with curcumin $(30 \mathrm{mg} / \mathrm{kg} \mathrm{BW})$ (DC30, $\square$ ); diabetic rats treated with curcumin $(60 \mathrm{mg} / \mathrm{kg} \mathrm{BW})(\mathrm{DC} 60$, $\longrightarrow$ ); diabetic rats treated with curcumin $(90 \mathrm{mg} / \mathrm{kg} \mathrm{BW})(\mathrm{DC} 90, \square \square-$; diabetic rats treated with insulin $(27.78 \mu \mathrm{mol})$ (DI, - - Repeatedmeasures ANOVA and Student-Newman-Keuls test were used for comparisons. Intergroup comparisons $(P<0.05)$ : †DC90 v. DY; $\ddagger D C 90 \quad v$. DW; $\S N D W, N D Y$, NDC90 v. DW, DY, DC30, DC60, DC90, DI; \|DI v. DW, DY, DC30, DC60, DC90; ๆ NDW, NDY, NDC90, DI v. DW, DY, DC30, DC60, DC90. Intragroup comparisons: ${ }^{\star} P<0.05$; with day 0 .

to secrete small amounts of insulin ${ }^{(11)}$. This hypothesis could also be applied to the present results. Nevertheless, a study by Suryanarayana et $a l^{(12)}$, who demonstrated a delay in STZ-induced cataract in rats, also reported that curcumin or powdered turmeric rhizomes mixed into the feed (0.5\%) did not alter glycaemia, insulinaemia or weight loss in diabetic animals. In fact, it would be interesting to compare the doses in the present study with those used by Suryanarayana et $a{ }^{(12)}$, but this is not possible, owing to the absence of data on food intake in the cited article. In addition, the difference between the vehicles used in the two studies should be taken into account, as it can influence the bioavailability of the curcumin.

Another hypothesis to explain the reduction in plasma glucose by curcumin is related to an increase in glucokinase activity $^{(11)}$. This enzyme is activated when intracellular glucose levels are raised; it converts glucose to glucose-6-phosphate, which is then stored in the liver in the form of glycogen ${ }^{(37)}$. We observed that the animals treated with curcumin (at $90 \mathrm{mg} / \mathrm{kg}$ BW per d) showed a rise in hepatic glycogenesis (Table 1). This hypothesis is strengthened by results obtained by Pari \& Murugan ${ }^{(38)}$ who observed the normalisation of activities of several key enzymes of carbohydrates metabolism; in this experiment, the metabolite tetrahydrocurcumin was more effective than curcumin.

A third possible mechanism by which curcumin could reduce hyperglycaemia relates to its antioxidant activity. Thus, Narayanasamy et al. ${ }^{(39)}$, using alloxan to induce experimental diabetes in rats, treated them with an aqueous suspension of curcumin $(0.8 \mathrm{~g} / \mathrm{kg} \mathrm{BW}$ per $\mathrm{d})$ or of powdered turmeric rhizomes $(1.0 \mathrm{~g} / \mathrm{kg} \mathrm{BW}$ per $\mathrm{d})$ and suggested that the antioxidant activity would diminish the oxidative damage to the pancreas in the treated rats, resulting in a relative increase in insulin secretion and hence a decrease in plasma glucose levels. Further published data also show that curcumin promotes a fall in the level of oxidative stress, indicated by low levels of thiobarbituric acid-reactive substances, which could be due to the reduction of glucose levels through the polyol pathway, leading to a higher NADPH:NADP ratio and

Table 2. Enzyme activities in serum of all experimental groups before and after $31 \mathrm{~d}$ of treatment

(Mean values with their standard errors $(n 8)$ )

\begin{tabular}{|c|c|c|c|c|c|c|c|c|c|c|c|c|}
\hline \multirow[b]{4}{*}{ Groups } & \multicolumn{12}{|c|}{ Day of treatment } \\
\hline & \multicolumn{2}{|c|}{0} & \multicolumn{2}{|c|}{31} & \multicolumn{2}{|c|}{0} & \multicolumn{2}{|c|}{31} & \multicolumn{2}{|c|}{0} & \multicolumn{2}{|c|}{31} \\
\hline & \multicolumn{4}{|c|}{ AST ( $\mu$ Kat) } & \multicolumn{4}{|c|}{ ALT ( $\mu$ Kat) } & \multicolumn{4}{|c|}{ ALP ( $\mu$ Kat) } \\
\hline & Mean & SEM & Mean & SEM & Mean & SEM & Mean & SEM & Mean & SEM & Mean & SEM \\
\hline DW & 1.31 & 0.05 & $8.00^{*}$ & 1.69 & $1 \cdot 13$ & 0.09 & $7 \cdot 44^{\star}$ & 2.03 & 12.61 & 1.55 & $21 \cdot 34^{*}$ & 3.95 \\
\hline DY & 2.09 & 0.54 & $7 \cdot 65^{\star}$ & 1.73 & 1.43 & 0.24 & $7 \cdot 28^{*}$ & $1 \cdot 78$ & 11.71 & 1.53 & $20 \cdot 89^{*}$ & $2 \cdot 92$ \\
\hline DC30 & 1.40 & $0 \cdot 10$ & $7 \cdot 34^{\star}$ & 1.57 & 1.25 & 0.09 & $5 \cdot 75^{\star}$ & 1.23 & $11 \cdot 72$ & 2.74 & $21 \cdot 23^{*}$ & 3.34 \\
\hline DC60 & 1.62 & 0.11 & $6 \cdot 17^{\star}$ & 38.7 & 1.52 & 0.30 & $4.53^{\star \star, \star}$ & 0.10 & 11.87 & 1.65 & $19 \cdot 65^{\star}$ & 2.56 \\
\hline DC90 & 1.69 & 0.01 & $5 \cdot 17 \dagger^{*}$ & 0.64 & 1.22 & 0.07 & $4.11 \dagger^{*}$ & 0.68 & 12.35 & 2.05 & $15 \cdot 00 \dagger$ & 1.64 \\
\hline DI & 1.51 & 0.16 & $4 \cdot 15 \ddagger^{*}$ & 0.36 & 1.20 & 0.09 & $1.72 \S$ & 0.19 & 12.53 & 1.56 & $9.78 \S$ & 1.70 \\
\hline NDW & 1.50 & 0.03 & $1.49 \|$ & 0.02 & 1.01 & 0.04 & $0.98 \|$ & 0.04 & 8.00 & 0.42 & 8.029 & 4.36 \\
\hline NDY & 1.55 & 0.05 & $1 \cdot 53 \|$ & 0.03 & 1.03 & 0.04 & $1.06 \|$ & 0.04 & 7.91 & 0.30 & 7.931 & 4.44 \\
\hline NDC90 & 1.58 & 0.06 & $1.58 \|$ & 0.06 & $1 \cdot 11$ & 0.05 & $1 \cdot 12 \|$ & 0.07 & 8.01 & 0.39 & 8.059 & 3.03 \\
\hline
\end{tabular}

ALT, alanine aminotransferase; AST, aspartate aminotransferase; ALP, alkaline phosphatase; DW, diabetic rats treated with water; DY, diabetic rats treated with yoghurt; DC30, diabetic rats treated with curcumin $(30 \mathrm{mg} / \mathrm{kg}$ body weight (BW)); DC60, diabetic rats treated with curcumin (60 mg/kg BW); DC90, diabetic rats treated with curcumin $(90 \mathrm{mg} / \mathrm{kg} \mathrm{BW})$; DI, diabetic rats treated with insulin $(27.78 \mu \mathrm{mol})$; NDW, non-diabetic rats treated with water; NDY, non-diabetic rats treated with yoghurt; NDC90, nondiabetic rats treated with curcumin $(90 \mathrm{mg} / \mathrm{kg} \mathrm{BW})$

Intergroup comparisons $(P<0.05)$ : †DC90 v. DW, DY; ¥DI v. DW, DY, DC30, DC60; §DI v. DW, DY, DC30, DC60, DC90; ॥ NDW, NDY, NDC90 v. DW, DY, DC30, DC60, DC90, DI; 9 NDW, NDY, NDC90, DI v. DW, DY, DC30, DC60, DC90; ${ }^{\star \star}$ DC60 vs. DW, DY. Intragroup comparisons: ${ }^{\star} P<0.05 ;$ with day 0 (repeated-measures ANOVA and Student-Newman-Keuls test were used for comparisons). 
consequently a higher level of glutathione peroxidase, a potent antioxidant enzyme ${ }^{(40)}$.

Despite the hypothetical mechanisms referred to previously, we found that curcumin does not promote a fall in blood glucose in ND rats (Table 1 and Fig. 2). This suggests that, at least in part, the mechanism for the action of curcumin involves a pathway independent of insulin. This notion is supported by data showing that, in the presence of $10 \mathrm{~nm}$-insulin, the addition of $25 \mu \mathrm{M}$-curcumin to isolated mouse hepatocytes enhanced the inhibitory effect of insulin on hepatic gluconeogenesis, which demonstrated that curcumin inhibits hepatic gluconeogenesis by a pathway independent of insulin ${ }^{(41)}$. This mechanism of reducing the level of blood glucose, independent of insulin, is also seen in the action of metformin (biguanide) the well-known hypoglycaemic drug ${ }^{(42)}$. A recent report indicates that curcumin and insulin together produce a synergistic anti-hyperglycaemic effect on muscle cell glucose metabolism in the mouse myoblast cell line ${ }^{(43)}$.

The DM syndrome is accompanied by changes in lipid metabolism ${ }^{(44)}$. In this study, there were significant decreases in both total cholesterol and TAG in group DI, relative to the other diabetic groups, while in group DC90 we observed a significant fall only in the TAG level, relative to group DW. Since curcumin activates hepatic acyl-CoA oxidase, which is responsible for the first step in the oxidation of fatty $\operatorname{acids}^{(10)}$, it has been proposed that curcumin stimulates fatty acid oxidation rather than adipogenesis in its anti-diabetic effect, thus contributing to the lowering of lipid levels in patients $^{(45)}$ and animals ${ }^{(10,46)}$. However, there are data that contradict these claims; thus Baum et al. ${ }^{(47)}$ observed no such effects on TAG levels.

Our investigation of the serum levels of cholesterol and HDL-cholesterol showed that curcumin had no effect. Baum et $a l .{ }^{(47)}$ also observed no effect on the levels of these lipids in men and women, who took curcumin in capsules or as a food supplement for 6 months. On the other hand, there are published reports in which curcumin influenced the progression of diabetes by diminishing lipid peroxidation by a mechanism initially attributed to the hypocholesterolaemic influence of curcumin ${ }^{(48)}$.

Diabetes is known to provoke raised levels of hepatic enzymes such as AST, ALT and ALP in the blood ${ }^{(8,34)}$. We found that animals treated with curcumin at a dose of $90 \mathrm{mg} / \mathrm{kg}$ BW per $\mathrm{d}$ exhibited lower levels of these activities than the rats in DW and DY for all three enzymes and at $60 \mathrm{mg} / \mathrm{kg}$ BW per d for ALT alone. These results confer on curcumin a hepatoprotective role, as also reported by Hussein et $a{ }^{(8)}$. It is well worth noting that the fall in AST activity was clearly dose-dependent, albeit significantly different from DW and DY for DC90 alone.

Our results demonstrate that, in diabetic rats, curcumin (group DC90) was capable of improving glycaemic levels, as well as the other markers for diabetes under study. Among the various hypothetical mechanisms by which curcumin could improve the metabolic state in diabetes, the present results are suggestive of a rise in glycogenesis.

On the basis of these results, we can state that curcuminsupplemented yoghurt possesses anti-diabetic activity, as it led to an improvement in all the classical markers for experimental diabetes, suggesting the potential use of yoghurt as a vehicle for the treatment of diabetes with curcumin. Further research is under way, to investigate the pharmacokinetics of curcumin-supplemented yoghurt following its introduction by gavage, as well as its possible cooperation with insulin.

\section{Acknowledgements}

The authors wish to thank the Brazil National Research and Development Council (CNPq), Foundation for the Development of the São Paulo State University (FUNDUNESP), the Scientific Research Aid Program of the Araraquara School of Pharmaceutical Sciences, UNESP (PADC-FCF-AraraquaraUNESP) and the São Paulo State Research Aid Foundation (FAPESP) for the financial support. The authors are also grateful to Marcos Dangona for his technical assistance. V. O. G., C. M. P., R. P. A., R. C. V., M. T. P. and I. L. B. disclose no conflicts of interest. M. T. P. and I. L. B. designed the study, analysed and interpreted the data and corrected the manuscript; V. O. G., C. M. P. and M. T. P. carried out the experiments and the physiological determinations; V. O. G., C. M. P., R. P. A. and R. C. V. performed the biochemical determinations; all authors read and approved the final version of the manuscript.

\section{References}

1. Sacks DB (2006) Carbohydrates. In Tietz Textbook of Clinical Chemistry and Molecular Diagnostics, 4th ed., pp. 837-867 [CA Burtis, ER Ashwood and DE Bruns, editors]. St Louis, MO: Elsevier Saunders.

2. Shaw JE, Sicree RA \& Zimment PZ (2010) Global estimates of the prevalence of diabetes for 2010 and 2030. Diabetes Res Clin Pract 87, 4-14.

3. Siró I, Kálpona E, Kálpona B, et al. (2008) Functional food. Product development, marketing and consumer acceptance - a review. Appetite 51, 456-467.

4. He M, Yang H, Han JH, et al. (2005) Effects of yoghurt supplementation on the growth of preschool children in Beijing suburbs. Biomed Environ Sci 18, 192-197.

5. Apostolidis E, Knon YI \& Shetty K (2006) Potential of select yogurts for diabetes and hypertension management. J Food Biochem 30, 699-717.

6. Epstein J, Sanderson IAN \& MacDonald TT (2009) Curcumin as a the therapeutic agent: the evidence from in vitro, animal and human studies. Br J Nutr 103, 1545-1557.

7. Nisshiyama T, Mae T \& Kishida H (2005) Curcuminoids and sesquiterpenoids in turmeric (Curcuma longa L.) suppress and increase in blood glucose level in type 2 diabetic KK-Ay mice. J Agric Food Chem 53, 959-963.

8. Hussein HK \& Abu-Zinadah OA (2010) Antioxidant effect of curcumin extracts in induced diabetic wister rats. Int J Zool $\operatorname{Res}$ 6, 266-276.

9. Babu P \& Srinivasan K (1997) Hypolipidemic action of curcumin, the active principle of turmeric Curcuma longa in streptozotocin induced diabetic rats. Mol Cell Biochem 166, 169-175.

10. Asai A \& Miyazawa T (2001) Dietary curcuminoids prevent high-fat diet-induced lipid accumulation in rat liver and epididymal adipose tissue. J Nutr 131, 2932-2935.

11. Seo KII, Choi MS, Jung UJ, et al. (2008) Effect of curcumin supplementation on blood glucose, plasma insulin, and 
homeostasis related enzyme activities in diabetic $\mathrm{db} / \mathrm{db}$ mice. Mol Nutr Food Res 52, 995-1004.

12. Suryanarayana P, Saraswat M, Mrudula T, et al. (2005) Curcumin and turmeric delay streptozotocin-induced diabetic cataract in rats. Invest Ophtalmol Vis Sci 6, 2092-2099.

13. Sharma S, Kulkarni S \& Chopra K (2006) Curcumin the active principle of turmeric (Curcuma longa), ameliorates diabetic nephropathy in rats. Clin Exp Pharmacol Physiol 33, 940-945.

14. Babu PS \& Srinivasan K (1998) Amelioration of renal lesions associated with diabetes by dietary curcumin in streptozotocin diabetic rats. $\mathrm{Mol}$ Cell Biochem 181, 87-96.

15. Dutta S, Padhye S, Priyadarsini KI, et al. (2005) Antioxidant and antiproliferative activity of curcumin semicarbazone. Bioorg Med Chem Lett 15, 2738-2744.

16. Goel A, Kunnumakkara AB \& Aggarwal B (2008) Curcumin as "Curecumin": from kitchen to clinic. Biochem Pharmacol 75, 787-809.

17. Shankar T, Shantha N, Ramesh H, et al. (1980) Toxicity studies on turmeric (Curcuma longa): acute toxicity studies in rats, guineapigs \& monkeys. Indian J Exp Biol 18, 73-75.

18. Lao C, Ruffin M, Normolle D, et al. (2006) Dose escalation of a curcuminoid formulation. BMC Complement Altern Med 6 , $10-15$.

19. Anand P, Kunnumakkara AB, Newman RA, et al. (2007) Bioavailability of curcumin: problems and promises. Mol Pharm 4, 807-818.

20. Shaik J, Ankola DD, Beniwal V, et al. (2009) Nanoparticle encapsulation improves oral bioavailability of curcumin by at least 9-fold when compared to curcumin administered with piperine as absorption enhancer. Eur J Pharm Sci 37, 223-230

21. Chen C, Johnston TD, Jeon H, et al. (2009) An in vitro study of liposomal curcumin: stability, toxicity and biological activity in human lymphocytes and Epstein-Barr virus-transformed human B-cells. Int J Pharm 36, 133-139.

22. Maiti K, Mukherjee K, Gantait A, et al. (2007) Curcuminphospholipid complex: preparation, therapeutic evaluation and pharmacokinetic study in rats. Int J Pharm 330, 155-163

23. Shoba G, Joy D, Joseph T, et al. (1998) Influence of piperine on the pharmacokinetics of curcumin in animals and human volunteers. Planta Med 64, 353-356.

24. Trinder P (1969) Determination of glucose in blood using glucose oxidase with alternative oxygen acceptor. Ann Clin Biochem 6, 24-27.

25. The Committee on Enzyme of Scandinavian Society for Clinical Chemistry and Clinical Physiology (1974) Recommended methods for the determination of four enzymes in blood. Scand J Clin Lab Invest 33, 291-306.

26. Tietz NW, Rinker AD \& Shaw LM (1983) IFCC methods for the measurement of catalytic concentraction of enzymes. Part 5. IFCC method for alkaline phosphatase (orthphosphoric-monoester phosphohydrolase, alkaline optimum, EC 3.1.3.1). J Clin Chem Clin Biochem 21, 731-748.

27. Rifai N \& Warnick GR (2006) Lipids, lipoproteins, apolipoproteins, and other cardiovascular risk factors. In Tietz Textbook of Clinical Chemistry and Molecular Diagnostics, 4th ed., pp. 903-981 [CA Burtis, ER Ashwood and DE Bruns, editors]. St Louis, MO: Elsevier Saunders.

28. Sugiuchi H \& Okabe H (2002) Development of homogeneous assay for HDL-C in serum. Risho Byori 50, 226-233.
29. Bradford MM (1976) A rapid and sensitive method for quantitation of microgram quantities of protein utilizing the principle of protein dye binding. Anal Biochem 72, 248-254.

30. Bergmeyer HU (1985) Methods of Enzymatic Analysis, 3rd ed., pp. 449-453 [HU Bergmeyer, J Bergmeyer and M Grassl, editors]. Deerfield Beach, FL: Verlag Chemie.

31. Dubowski KM (1962) An o-toluidine method for body fluid glucose determination. Clin Chem 8, 215-235.

32. Vies VD (1953) Two methods for the determination of glycogen in liver. Pharmacol Res 57, 410-416.

33. Al-Awwadi N, Azay J, Poucheret P, et al. (2004) Antidiabetic activity of red wine polyphenolic extract, ethanol, or both in streptozotocin-treated rats. J Agric Food Chem 52, 1008-1016.

34. Mori DM, Baviera AM, Ramalho LTO, et al. (2003) Temporal response pattern of biochemical analytes in experimental diabetes. Biotechnol Appl Biochem 38, 183-191.

35. Sarkhail P, Rahmaipour S, Fadyevatan S, et al. (2007) Antidiabetic effect of Phlomis anisodonta: effects on hepatic cells lipid peroxidation and antioxidant enzymes in experimental diabetes. Pharmacol Res 56, 261-266.

36. Sekiya M, Yahagi N, Tamura Y, et al. (2009) Hormonesensitive lipase deficiency suppresses insulin secretion from pancreatic islet of Lep ob/ob mice. Biochem Biophys Res Commun 387, 511-515.

37. Zelent D, Najafi H, Odili S, et al. (2005) Glucokinase and glucose homeostasis: proven concepts and new ideas. Biochem Soc Trans 33, 306-310.

38. Pari L \& Murugan P (2005) Effect of tetrahydrocurcumin on blood glucose, plasma insulin and hepatic key enzymes in streptozotocin induced diabetic rats. J Basic Clin Physiol Pharmacol 4, 257-274.

39. Narayanasamy A, Namasivayam N \& Radha K (2003) Effect of tumeric on the enzymes of glucose metabolism in diabetic rats. J Herbs Spices Med Plants 10, 75-84.

40. Arun N \& Nalini N (2002) Efficacy of turmeric on blood sugar and polyol pathway in diabetic albino rats. Plants Foods Hum Nutr 1, 41-52.

41. Fujiwara H, Hosokawa M, Zhou X, et al. (2008) Curcumin inhibits glucose production in isolated mice hepatocytes. Diabetes Res Clin Pract 80, 185-191.

42. Mithieux G, Guignotl G, Bordet JC, et al. (2002) Intrahepatic mechanisms underlying the effect of metformin in decreasing basal glucose production in rats fed a high-fat diet. Diabetes 51, 139-143.

43. Kang C \& Kim E (2010) Synergistic effect of curcumin and insulin on muscle cell glucose metabolism. Food Chem Toxicol 48, 2366-2373.

44. Martin A, Sven-Olof O, Marja RT, et al. (2006) Diabetic dyslipidaemia. Curr Opin Lipidol 17, 238-246.

45. Soni Kb \& Kuttan R (1992) Effect of oral curcumin administration on serum peroxides and cholesterol levels in human volunteers. Indian J Physiol Pharmacol 36, 273-275.

46. Na LX, Zhang YL, Li Y, et al. (2011) Curcumin improves insulin resistance in skeletal muscle of rats. Nutr Metab Cardiovasc Dis 21, 526-533.

47. Baum L, Cheung SK, Mok VC, et al. (2007) Curcumin effects on blood lipid profile in 6-month human study. Pharmacol Res 56, 509-514

48. Babu PS \& Srinivasan K (1995) Influence of dietary curcumin and cholesterol on the progression of experimentally induced diabetes in albino rat. Mol Cell Biochem 1, 13-21. 